\section{Adverse Effects on PMMA Caused by Mechanical and Combined Methods of Denture Cleansing}

Danilo Balero Sorgini, Cláudia Helena da Silva-Lovato,Valdir Antônio Muglia, Raphael Freitas de Souza, Carolina Noronha Ferraz de Arruda, Helena de Freitas Oliveira Paranhos
Dental Materials and Prosthodontics Department, Dental School of Ribeirão Preto, USP - University of São Paulo, Ribeirão Preto, SP, Brazil

Correspondence: Profa. Dra Helena de Freitas Oliveira Paranhos, Avenida do Café, S/N, 14040-904 Ribeirão Preto, SP, Brasil. Tel: +55-16-33154031. e-mail: helenpar@forp.usp.br

\begin{abstract}
This study evaluated the abrasiveness of mechanical and combined methods of denture hygiene, by the analysis of mass loss and surface roughness. Acrylic resin specimens (Plexiglass) were brushed by a tooth brushing machine (Mavtec) with a soft brush (Tek) and water (control) or four dentifrices (Sorriso, Colgate, Polident and Corega) (Experimental groups) for 50 min, representing one year of brushing (mechanical method). After brushing, the specimens were immersed in 0.5\% sodium hypochlorite simulating a daily cleaning of $20 \mathrm{~min}$ for one year (combined method). Distilled water $\left(23^{\circ} \mathrm{C}\right.$ ) was employed as control. The mass loss $(\mathrm{g})$ was analyzed by an analytical balance and the surface roughness $(\mu \mathrm{m})$ by a rugosimeter. Data were subjected to ANOVA and Bonferroni test $(\alpha=0.05)$. Polident dentifrice showed lowest values of mass loss for both methods (mechanical: $-0.0072 \pm 0.0017$, combined:-0.011 \pm 0.002 ) and the combined method resulted in greater mass loss than the mechanical, except for Corega. For the surface roughness, after the mechanical method, the lowest values were registered for water $(-0.007 \pm 0.016)$ and Polident $(0.402 \pm 0.378)$; for the combined method, water $(-0.063 \pm 0.013)$ showed the lowest values; there was no statistically significant difference between methods. It was concluded that Polident was the less abrasive dentifrice and the association between chemical and mechanical methods increased the mass loss but did not change the surface roughness of specimens.
\end{abstract}

Key Words: complete denture, denture cleansers, dentifrices, sodium hypochlorite, adverse effects.

\section{Introduction}

The cleaning of complete dentures can be performed by mechanical, chemical and combined methods. Among the mechanical methods, brushing is widely employed and has been considered a simple, inexpensive and effective method to remove stains and organic deposits $(1,2)$. The main chemical method of denture cleansing consists in immersing the prosthetic devices in solutions with solvent, detergent, antibacterial and antifungal actions (3). Among the proposed solutions, sodium hypochlorite is widely indicated due to its antimicrobial characteristics and has been suggested as an effective denture cleanser (4-6).

The denture cleansers must be effective and not deleterious to materials of the prosthetic device (3). The adverse effects caused by these agents, when used as isolated method, have been reported in the literature. Thus, brushing can wear the denture base and artificial teeth (7-11) and hypochlorite solutions may alter color, surface roughness and flexion resistance of acrylic resins (12-15). However, the interaction between both methods has not been widely investigated.

In studies of the physical properties of acrylic resins, the analysis of mass loss and surface roughness caused by cleaning methods is extremely important. The mass loss due to brushing may interfere in the adjustment of complete dentures and also in its aesthetic effect, causing loss gloss and increased surface roughness $(8,10,11,16,17)$. Increased surface roughness makes the denture more susceptible to biofilm accumulation and difficult to maintain denture hygiene (16).

The current literature shows that the association of mechanical and chemical methods is effective $(1,6)$, therefore, it is important to investigate the adverse effects caused by this method of denture hygiene. This study evaluated the mass loss and surface roughness changes of acrylic resin specimens when submitted to mechanical (brushing with conventional and specific dentifrices) and combined (brushing and immersion) denture cleansing methods, in a period that corresponds to an exposition of one year use.

\section{Material and Methods Specimens}

Seventy-two rectangular specimens $(90 \mathrm{~mm} \times 30 \mathrm{~mm}$ $x 3 \mathrm{~mm}$ ) were fabricated from a polymethyl methacrylate plate (Plexiglass; Day Brasil SA, Ribeirão Preto, SP, Brazil), a substrate pressed at high temperatures and considered internationally acceptable for the analysis of dentifrice 
abrasiveness (18). As this substrate has been employed in previous studies $(2,8,10)$, it was used for comparative analyses. To standardize the local of surface roughness readings, the specimens were assigned with three markings (Stem conical bur; Microdont Precision Micro Machining Ltda., São Paulo, SP, Brazil), the first in the central region, corresponding to half the distance of its length and two drawn at $5 \mathrm{~mm}$ lateral to the first. After marking, the specimens were immersed in a container with distilled water and placed in an oven, at constant temperature (37 ${ }^{\circ} \mathrm{C}$ ) for water saturation of the acrylic resin and weighed weekly on an analytical balance (Metler Toledo, Greifensee, Switzerland) until constant mass was observed, indicating a steady state (19). In order to confirm this state of equilibrium, an additional 3 times longer period was applied following the weighing. This procedure was performed to balance water sorption and establish baseline values, since the specimens could have their weight altered by water sorption during the denture hygiene procedures.

\section{Denture Hygiene Methods}

The mechanical brushing test was performed in a brushing machine (Mavtec, Ribeirão Preto, SP, Brazil), in accordance with ISO/DTS 145691 specifications for wear testing (19). The specimens were brushed with soft toothbrushes with 26 nylon bristles $(0.25 \mathrm{~mm}$ diameter and $10 \mathrm{~mm}$ high per bundle) (Tek; Johnson \& Johnson, São José dos Campos, SP, Brazil). The machine worked at a rate of $356 \mathrm{rpm}$, a $200 \mathrm{~g}$ load and $3.8 \mathrm{~cm}$ path, brushing six specimens simultaneously. Distilled water $\left(23 \pm 3^{\circ} \mathrm{C}\right)$ and four dentifrices were used as suspensions. Two dentifrices were conventional: Sorriso and Colgate (ColgatePalmolive, Osasco, SP, Brazil), and two were specific for denture cleansing: Corega (GSK - GlaxoSmithKline, Rio de Janeiro, RJ, Brazil) and Polident (GSK - GlaxoSmithKline, Philadelphia, PA, USA). A volume of $80 \mathrm{~g}$ of each dentifrice was suspended in $80 \mathrm{~mL}$ of distilled water (1:1), mixed in plaster vacuum mixer and poured into the vats of the device, onto the specimens ( $12 \mathrm{~mL}$ for each specimen). The brushing time was 50 min (17,800 cycles), corresponding to a one year of exposure to brushing (20).

After the brushing test, the specimens were submitted to chemical tests, by immersion in $0.5 \%$ sodium hypochlorite solution (Daterra Prescription Pharmacy, Ribeirão Preto, $\mathrm{SP}, \mathrm{Brazil})$ in sealed containers at room temperature $(23 \pm 2$ $\left.{ }^{\circ} \mathrm{C}\right)$ and protected from light. This solution was employed due to its low cost, accessibility and efficacy $(4,5)$. This immersion procedure corresponded to an exposition of a daily cleaning of $20 \mathrm{~min}$ for 365 days, totaling $121 \mathrm{~h}$ and 30 min of immersion. The control group was immersed in distilled water at $23 \pm 2{ }^{\circ} \mathrm{C}$.

The following groups were obtained $(n=12)$ : 1.Control
(C): brushing with distilled water and immersion in distilled water; 2. Water (Experimental 1): brushing with distilled water and immersion in $0.5 \% \mathrm{NaClO} ; 3$. Sorriso (Experimental 2): brushing with Sorriso dentifrice and immersion in $0.5 \% \mathrm{NaClO} ; 4$. Colgate (Experimental 3): brushing with Colgate dentifrice and immersion in $0.5 \% \mathrm{NaClO} ; 5$. Polident (Experimental 4): brushing with Polident dentifrice and immersion in $0.5 \% \mathrm{NaClO}$; 6 . Corega (Experimental 5): brushing with Corega dentifrice and immersion in $0.5 \% \mathrm{NaClO}$.

\section{Abrasiveness Evaluation}

The mass loss was evaluated by the gravimetric method, which are the values of mass difference of specimens in $\mathrm{mg}$, before and after the tests. For each weighing, the specimens were rinsed in tap water, blotted dry and air heated for $15 \mathrm{~s}$. After $1 \mathrm{~min}$, they were weighed on an electronic analytical balance (Metler Toledo $\mathrm{GmbH}$, Laboratory \& Weighing Technologies, Greifensee, Switzerland) with 0.1 $\mathrm{mg}$ resolution and $210 \mathrm{~g}$ capacity. The weighing procedure was carried out before applying the denture hygiene methods (M1), after the brushing mechanical test (M2) and after the immersion test (M3). Mass loss (ML) was calculated in mg to obtain the mechanical method results (M2-M1) and combined method results (chemical and mechanical) (M3-M1).

The surface roughness change was obtained by calculating the surface roughness difference $(\mu \mathrm{m})$ at the same time of the weight loss, using a roughness tester (Surftest SJ-201P, Mitutoyo Corporation, Kawasaki, Japan). The specimens were fixed on the surface roughness measuring table with double sided tape. For each specimen there were three readings $4.0 \mathrm{~mm}$ long, $0.8 \mathrm{~mm}$ cut-off and at $0.5 \mathrm{~mm} / \mathrm{s}$ in the regions corresponding to the markings of the specimens. The arithmetic mean of the three measurements $(\mu \mathrm{m})$ was calculated. The surface roughness evaluation was carried out before applying the denture hygiene methods (R1), after the mechanical test of brushing (R2) and after the immersion test (R3). The changes in surface roughness (RA) were calculated $(\mu \mathrm{m})$, obtaining the results for the mechanical method (R2-R1) and the combined method (chemical and mechanical) (R3-R1).

After the data homoscedasticity test, they were analyzed separately by two-way ANOVA and Bonferroni test, using the Graphpad Prism program (GraphPad Software, Inc., La Jolla, CA, USA). Significance was set at 0.05 .

\section{Results}

\section{Mass Loss Evaluation}

Two-way ANOVA showed significant difference for denture hygiene methods, groups and also for their interaction $(p<0.0001)$ (Table 1). 
After the mechanical method application, brushing with dentifrices (conventional and specific) resulted in greater weight loss than brushing with water. Among the dentifrices, the highest values were found for Sorriso $(-0.016 \pm 0.004)$, Colgate $(-0.012 \pm 0.004)$ (conventional) and Corega $(-0.012 \pm 0.003)$ (specific) and the lowest for Polident $(-0.007 \pm 0.002)$ (specific). After applying the combined method, there were differences between the experimental and control groups. Comparing the dentifrices, the highest values were for Sorriso $(-0.018 \pm 0.005)$ and Colgate $(-0.015 \pm 0.003)$ and the lowest for Polident $(-0.011 \pm 0.002)$. Comparing the denture hygiene methods, the combined method resulted in greater mass loss than the mechanical method, except for the Corega group.

\section{Surface Roughness Evaluation}

Two-way ANOVA showed significant difference for the groups ( $p<0.0001)$, as well as the interaction among groups $(p=0.0007)$. There was no difference between denture hygiene methods $(p=0.3027)$. The results are presented in Table 2.

After applying the mechanical method, all dentifrices caused greater surface roughness change than water, except $\therefore$ Polident $(0.402 \pm 0.378)$. After the combined method, there were differences between the experimental and control groups, except for the water group (water $+0.5 \% \mathrm{HS}$ ), and the highest values were for the Sorriso $(1.617 \pm 1.190)$ and Corega $(1.634 \pm 1.082)$ groups.

\section{Discussion}

This study evaluated the mass loss and surface roughness changes of Plexiglass acrylic (PMMA), when subjected to mechanical and combined denture cleansing methods. After applying the mechanical method (brushing), all dentifrices caused greater weight loss than the control group (water). This result may be explained by the low abrasion resistance

Table 1. Mass loss (mg) after application of denture hygiene methods. Mean values and comparison by pairs

\begin{tabular}{|c|c|c|}
\hline \multirow{2}{*}{ Groups } & \multicolumn{2}{|c|}{ Hygiene methods } \\
\hline & Mechanical & Combined \\
\hline Control & $0.000 \pm 0.001(\mathrm{~A}, \mathrm{a})$ & $0.000 \pm 0.001(\mathrm{~A}, \mathrm{a})$ \\
\hline Water & $0.000 \pm 0.000(\mathrm{~A}, \mathrm{a})$ & $-0.005 \pm 0.001(\mathrm{~B}, \mathrm{~b})$ \\
\hline Sorriso & $-0.016 \pm 0.004(A, c)$ & $-0.018 \pm 0.005(\mathrm{~B}, \mathrm{e})$ \\
\hline Colgate & $-0.012 \pm 0.004(\mathrm{~A}, \mathrm{c})$ & $-0.015 \pm 0.003(\mathrm{~B}, \mathrm{~d}, \mathrm{e})$ \\
\hline Polident & $-0.007 \pm 0.002(A, b)$ & $-0.011 \pm 0.002(\mathrm{~B}, \mathrm{c})$ \\
\hline Corega & $-0.012 \pm 0.003(\mathrm{~A}, \mathrm{c})$ & $-0.013 \pm 0.004(A, c, d)$ \\
\hline
\end{tabular}

Different letters indicate statistically significant difference $(p<0.05)$. Uppercase: between hygiene methods; lowercase: among groups. of acrylic resin, resulting in mass loss due to brushing with dentifrices $(2,7-11)$. However, it is important to differentiate abrasiveness between conventional and specific denture dentifrices since low abrasiveness is one of the main requirements for denture dentifrice $(3,22)$. The most abrasive dentifrices were Sorriso, Colgate and Corega.

Previous studies showed high abrasiveness of these conventional dentifrices over acrylic resin artificial teeth (7) and polymethyl methacrylate (PMMA) (8-11). Sorriso contains calcium carbonate and sodium bicarbonate, conforming with ISO 737 standard, which provides moderate/mean abrasiveness to a dentifrice (21). Colgate dentifrice, which has the same formulation as Sorriso, is also included in that classification. Freitas and Paranhos (7) showed, by microscopic analysis, that Colgate's abrasive particles presented an irregular spherical form, irregular size and heterogeneous distribution, producing a greater abrasiveness.

Studies have shown that specific dentifrices with small and regular abrasive particles and homogeneous distribution (7) or even without abrasive particles (9) caused less abrasion in Plexiglass acrylic (PMMA) and in heatpolymerized acrylic resins. The specific dentifrice Corega has an abrasive system composed of sodium bicarbonate and silica. In addition to its low abrasiveness, the silica particle is relatively soluble in water (2), which causes less mass loss and provides greater polishing to the surface (8). The topography of silica particles can explain such characteristics, as their solubility may result in rounding off of sharp angles and thus promotes polishing of the surface. Previous results do not suggest that mass loss is closely linked to roughness (8). The mass loss depends on particle abrasiveness, and pressure, speed and time of the procedure, as well as the hardness of the material under abrasion. Regardless of the mass loss, the surface roughness depends on particle conditions and the shape of the used

Table 2. Differences in surface roughness $(\mu \mathrm{m})$ after application of denture hygiene methods. Mean values and comparison in pairs

\begin{tabular}{lcc}
\hline \multirow{2}{*}{ Groups } & \multicolumn{2}{c}{ Hygiene methods } \\
\cline { 2 - 3 } Control & $0.005 \pm 0.005$ (a) & $0.004 \pm 0.006$ (a) \\
Water & $-0.007 \pm 0.016$ (a) & $-0.063 \pm 0.013$ (a) \\
Sorriso & $1.755 \pm 1.291$ (b) & $1.617 \pm 1.190$ (c) \\
Colgate & $1.421 \pm 0.964$ (b) & $0.710 \pm 0.482$ (b) \\
Polident & $0.402 \pm 0.378$ (a) & $0.817 \pm 0.867$ (b) \\
Corega & $1.564 \pm 1.174$ (b) & $1.634 \pm 1.082$ (c) \\
\hline
\end{tabular}

Different letters indicate statistically significant difference among groups $(p<0.05)$. 
particles has different effects on surface finishing $(10,16)$. Despite this, the results were similar to other studies $(8,10)$, where its abrasiveness was similar to conventional toothpastes, confirming that the abrasive agent is not the only determinant for more or less abrasiveness. Lara and Panzeri (18) verified that one important factor to be considered for the conditioning of abrasiveness is the interaction between the abrasive system and the type of thickener employed in the dentifrice formulations.

The lowest mass loss occurred for the Polident dentifrice (specific). These results are in agreement with previous studies that employed acrylic resins and artificial teeth as substrate and found that the Dentu Creme, a specific dentifrice for complete denture which contains the same abrasive system of Polident, was considered of low abrasiveness $(7,9)$. The obtained results also showed low abrasiveness in Plexiglass acrylic (cast PMMA). Furthermore, Polident showed the low abrasion requirement, since it did not differ from the control group. Polident, as well as Colgate and Sorriso, has calcium carbonate as abrasive, but it also has glycerin in its formulation, which is responsible for the lowest abrasion values due to its lubricating effect (23).

In the association of brushing to the chemical method (combined method) there were differences between the control and experimental groups suggesting that immersion in $0.5 \%$ sodium hypochlorite results in mass loss. The literature is scarce regarding mass changes of acrylic resin after immersion in denture cleansers. There were no weight changes of specimens made of acrylic resin and different metal alloys after immersion in sodium hypochlorite solution in a simulation period of six months, but the employed concentration was $0.05 \%$ (24). The mass loss was not found for the Corega group, which may be explained by the presence of titanium dioxide in its composition, a white pigment widely used as an opacifying agent. This component is added to the formulation of certain toothpastes in order to simulate the whitening effect of teeth, and may have decreased the abrasiveness resulting in lower mass loss. After applying the mechanical method, Corega specimens showed an opaque and white film over its entire surface, which may have hindered the mass loss.

The analysis of surface roughness changes after applying the mechanical method showed the highest values for the Sorriso, Polident and Colgate groups. Studies have shown that brushing with toothpaste increases the surface roughness $(11,16,17)$, but low $R a$ values are favorable, provided they are accompanied by cleaning efficiency, as they reduce the biofilm development and stains on the surface of complete dentures. The results of this study agree with a previous study (8), in which the highest values of Ra were related to the Sorriso toothpaste. The lowest Ra values were obtained for the Polident group, a fact that shows that the scratches caused by toothpastes during brushing are not only the results of the type of abrasive particle, but also of their shape (16).

When the specimens were subjected to the combined cleaning method, the lowest values were associated with the water and control groups, suggesting that the surface roughness change may have occurred due to the type of dentifrice used and not of the immersion agent since the same surface roughness change standard was maintained after the application of the combined method. For the groups that used brushing with toothpaste, Polident obtained the lowest values, even after the mechanical method was applied.

There are reports of surface roughness changes when sodium hypochlorite is used for denture cleansing, but if employed as an isolated method. Previous studies analyzed the surface roughness changes of heat- and microwavepolymerized acrylic resins after use of $0.5 \%$ and $1 \%$ sodium hypochlorite solutions, simulating immersions of $20 \mathrm{~min}$ and $8 \mathrm{~h}$ showing no significant changes in simulated periods of 6 and 18 months $(13,15)$. Similar results for $1 \%$ sodium hypochlorite were obtained, but for seven days (12).

The results of mass loss and surface roughness change for Corega disagree with the properties required for a specific denture cleanser dentifrice, since their high results for both analyses were similar to the conventional dentifrices. Analyzing the mass loss and surface roughness simultaneously, the low abrasiveness of Polident is confirmed, which may be a result of its formulation, the association of a thickener to the abrasive particle (2) or the shape of the abrasive particles (16). This is a result of clinical relevance because one of the important requirements of a specific denture-cleansing dentifrice is the low abrasiveness to prevent acrylic resin wear (22).

The combination of chemical and mechanical methods increased the mass loss values, but caused no surface roughness change. This result may be explained by the fact that immersion in hypochlorite solutions did not cause significant changes on surface roughness of acrylic resins $(4,5,13-15)$. The present results indicate that this property was not altered by this solution even when employed in association to brushing. Surface roughness changes in acrylic resin (Lucitone 550) after the use of combined method (brushing and immersion) was not verified, but with $4 \%$ chlorhexidine solution and the hygienic procedures were performed twice or seven times (25).

Regarding the study limitation, besides the used simulation time, a factor that may be stressed refers to the non-reproduction of specific oral conditions in this methodology, such as the presence of biofilm, a variable that could influence the action of chemical denture cleansers (1). 
Thus, studies should be carried out to analyze the adverse effects caused by the combined method on acrylic resins for denture bases, simulating the oral environment. Other chemical solutions should be evaluated, like effervescent alkaline peroxide, a product widely indicated as denture cleanser (3).

Based on the applied methodology and on the analysis of the results, it was concluded that Polident was the less abrasive dentifrice and the association between chemical and mechanical methods increased the mass loss but did not change the surface roughness of specimens.

\section{Resumo}

Este estudo avaliou a abrasividade causada pelos métodos mecânico e combinado de higiene de próteses totais, por meio da análise da perda de massa e rugosidade de superfície. Corpos de prova de resina acrílica (Plexiglass) foram escovados em máquina de escovação (Mavtec) com escova macia (Tek) e água ou dentifricios (Sorriso, Colgate, Polident e Corega) (Grupos Experimentais) por $50 \mathrm{~min}$, simulando 1 ano de escovação (método mecânico). Após a escovação, os corpos de prova foram imersos em hipoclorito de sódio a 0,5\%, simulando imersões diárias de 20 min por 1 ano (método combinado). Água destilada $\left(23^{\circ} \mathrm{C}\right)$ foi empregada como controle. A perda de massa foi analisada por meio de balança analítica de precisão $(\mathrm{g})$ e a rugosidade de superficie por rugosimetro $(\mu \mathrm{m})$. Os dados foram submetidos à ANOVA e teste de Bonferroni $(\alpha=0,05)$. Em relação à perda de massa, os menores valores foram obtidos para o Polident em ¿̇ ambos os métodos (mecânico: $-0,0072 \pm 0,0017$; combinado: $-0,011 \pm 0,002$ )

¿ e o método combinado resultou em maior perda de massa que o método . mecânico, exceto para o Corega. Para a rugosidade de superficie, após aplicação do método mecânico, os valores mais baixos foram registrados para água $(-0,007 \pm 0,016)$ e Polident $(0,402 \pm 0,378)$; para o método combinado, os valores mais baixos foram obtidos para água $(-0,063 \pm 0,013)$; não houve diferença estatística entre os métodos. Conclui-se que o Polident foi o dentifrício menos abrasivo e que a associação do método químico ao método mecânico aumentou a perda de massa, porém não alterou a rugosidade de superficie dos corpos de prova.

\section{Acknowledgements}

The authors thank FAPESP for the financial support (grant No. 2010/185828) and Viviane C. Oliveira (laboratory technician) for the support provided during the development of the study.

\section{References}

1. Paranhos HFO, Silva-Lovato $\mathrm{CH}$, Souza RF, Cruz PC, Freitas KM, Peracini A. Effects of mechanical and chemical methods on denture biofilm accumulation. J Oral Rehabil 2007;34:606-612.

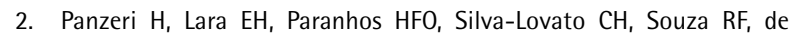
Souza Gugelmin MC, et al.. In vitro and clinical evaluation of specific dentifrices for complete denture hygiene. Gerodontology 2009;26:2633.

3. Council on Dental Materials, Instruments and Equipments. Denture cleansers. J Am Dent Assoc 1983;106:77-79.

4. Lima EM, Moura JS, Del Bel Cury AA, Garcia RC, Cury JA. Effect of enzymatic and $\mathrm{NaOCl}$ treatments on acrylic roughness and on biofilm accumulation. J Oral Rehabil 2006;33:356-362.

5. Sousa Porta SR, Lucena-Ferreira SC, Da Silva WJ, Del Bel Cury AA. Evaluation of sodium hypochlorite as a denture cleanser: a clinical study. Gerodontology 2013;12. [Epub ahead of print. DOI: 10.1111/ ger.12104.

6. Andrade IM, Andrade KM, Pisani MX, Silva-Lovato $\mathrm{CH}$, de Souza RF,
Paranhos HFO. Trial of an experimental castor oil solution for cleaning dentures. Braz Dent J 2014;25:43-47.

7. Freitas KM, Paranhos HFO. Weight loss of five commercially available denture teeth after toothbrushing with three different dentifrices. J Appl Oral Sci 2006;14:242-246.

8. Pisani MX, Bruhn JP, Paranhos HFO, Silva-Lovato CH, Souza RF, Panzeri $\mathrm{H}$. Evaluation of the abrasiveness of dentifrices for complete dentures. J Prosthodont 2010;19:369-373.

9. Freitas-Pontes KM, Silva-Lovato $\mathrm{CH}$, Paranhos HFO. Mass loss of four commercially available heat-polymerized acrylic resins after tooth brushing with three different dentifrices. J Appl Oral Sci 2009;17:116121.

10. Sorgini $\mathrm{DB}$, Silva-Lovato $\mathrm{CH}$, Souza RF, Davi LR, Paranhos HFO. Abrasiveness of conventional and specific denture-cleansing dentifrices. Braz Dent J 2012;23:154-159.

11. Machado AL, Giampaolo ET, Vergani CE, Pavarina AC, da Silva Lopes Salles $\mathrm{D}$, Jorge JH. Weight loss and changes in surface roughness of denture base and reline materials after simulated toothbrushing in vitro. Gerodontology 2012;29:e121-e127.

12. Azevedo $A$, Machado $A L$, Vergani $C E$, Giampaolo ET, Pavarina $A C$, Magnani R. Effect of disinfectants on the hardness and roughness of reline acrylic resins. J Prosthodont 2006;15:235-242.

13. Paranhos HFO, Davi LR, Peracini A, Soares RB, Lovato CH, Souza RF. Comparison of physical and mechanical properties of microwavepolymerized acrylic resin after disinfection in sodium hypochlorite solutions. Braz Dent J 2009;20:331-335.

14. Lira AF, Consani RL, Mesquita MF, Nóbilo MA, Henriques GE. Effect of tooth brushing, chemical disinfection and thermocycling procedures on the surface microroughness of denture base acrylic resins. Gerodontology 2012;29:891-897.

15. Paranhos HFO, Peracini A, Pisani MX, Oliveira VC, Souza RF, Silva-Lovato $\mathrm{CH}$. Color stability, surface roughness and flexural strength of an acrylic resin submitted to simulated overnight immersion in denture cleansers. Braz Dent J 2013;24:152-156.

16. Harrison Z, Johnson A, Douglas CW. An in vitro study into the effect of a limited range of denture cleaners on surface roughness and removal of Candida albicans from conventional heat-cured acrylic resin denture base material. J Oral Rehabil 2004;31:460-467.

17. Oliveira LV, Mesquita MF, Henriques GE, Consani RL, Fragoso WS. Effect of polishing technique and brushing on surface roughness of acrylic resins. J Prosthodont 2008:17:308-311.

18. Lara EHG, Panzeri H. Study of the abrasiveness of basic dentifrices formulations. Rev Cienc Farm São Paulo 1998;19:207-224.

19. International Organization for Standardization. Technical Specification 14569-1. Dental Materials - Guidance on testing of wear resistance Part 1: Wear by tooth brushing. Geneva, ISO;1999.

20. Vieira DF, Phillips RW. Influence of certain variables on the abrasion of acrylic resin veneering materials. J Prosthet Dent 1962;12:720-731.

21. ADA. American National Standard: Specification \#37 for dental abrasive powders. 1986, pp.319-331.

22. Richmond R, Macfarlane TV, McCord JF. An evaluation of the surface changes in PMMA biomaterial formulations as a result of toothbrush/ dentifrice abrasion. Dent Mater 2004;20:124-132.

23. Harte DB, Manly RS. Four variables affecting magnitude of dentifrice abrasiveness. J Dent Res 1976;55:322-327.

24. Felipucci DN, Davi LR, Paranhos HFO, Bezzon OL, Silva RF, Barbosa

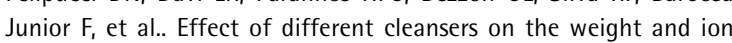
release of removable partial denture: an in vitro study. J Appl Oral Sci 2011;19:483-487.

25. Machado AL, Giampaolo ET, Pavarina AC, Jorge JH, Vergani CE. Surface roughness of denture base and reline materials after disinfection by immersion in chlorhexidine or microwave irradiation. Gerodontology 2012;29:e375-e382. 